point being a short paper describing usually some very recent experimental observations made by the main speaker and followed by a discussion, often animated and always rewarding, bearing upon the topic under consideration. In this way the reader is presented with new information and with the reaction of others best qualified to judge its significance. Vol. V of this series of Colloquia is concerned with the bioassay of anterior pituitary and adrenocortical hormones. The first speaker, Albert Segaloff, has defined the requirements which must be met by the ideal assay. It should be : (I) Specific; (2) reproducible from laboratory to laboratory; (3) sensitive; (4) statistically sound; (5) simple; (6) rapid; (7) inexpensive. Of these the first four are essential. It is clear from considering the facts presented in the rest of the volume that few, if any, of the present bioassay methods meet these requirements in full, and many of them are deficient even in the essential ones. Segaloff also records that "it is amazing how many physicians think that all endocrinological diagnoses can be made on a poorly collected, haphazardly refrigerated 24-hour urine specimen.' This criticism applies with equal force to other branches of biochemical investigation at the clinical level, and there is no doubt that many procedures begin and end with an inadequate urine collection. Although the material presented in this volume is primarily intended for the specialist and research worker, it would repay perusal by those concerned in the clinical management of patients, if only to indicate to them the complexities of the subject and the impossibility, at the present time, of providing them with precise information so urgently required in the diagnosis of frank endocrinological disorders, and for the understanding of the metabolic problem in conditions superficially distinct from them for example in cardiac, hepatic and renal failure, and in chronic ill health generally.

This book will be read eagerly by the specialist and by the physician who wishes to be critically informed about the methods upon which he must rely in deriving quantitative and semi-quantitative information of the hormone concentrations in the body fluid. The Ciba Foundation is making a valuable contribution to biological science by arranging these colloquia and in publishing the results with as little time delay as possible.

V.W.

\section{AN APPROACH TO CLINICAL SURGERY}

By G. H. C. Ovens, O.B.E., M.B., B.S., F.R.C.S.

Pp. vii +309 , with 118 illustrations. London:

J. \& A. Churchill, Ltd. I953. 22s. 6d.

Teachers of surgery agree that the first months of clinical teaching are both the most important and the most difficult. This book by Professor Ovens is intended to cover this period and it succeeds in its object. Any student entering the wards of a hospital for the first time will find it of great help. The first edition of a book often contains omissions or errors; one function of a reviewer is to point out those he notices so that they can be corrected in future editions.
There are two major omissions from this book. Carcinoma of the bronchus, which in Britain today is the commonest new growth and a common reason for attendance at surgical out-patients or admission to surgical wards, is not mentioned. The importance of this omission from a textbook of this type may be gauged from this recent statement by a senior clinician: "When I was a young man if I saw a patient with a swelling and I did not know what it was I used to say that it was syphilitic and I was nearly always right. Today I say that it is a secondary from carcinoma of the bronchus.' The other omission is that the tests for the function of the peripheral nerves have not been included. Fig. Ir 7 on page 301 illustrates an ulnar nerve lesion, but the book does not tell the student how to examine such a patient.

This textbook is recommended to all students who are commencing their hospital work and their teachers also will benefit from reading it. It should be successful and pass through many editions.

C.C.R.

\section{KIELLAND'S FORCEPS}

By E. Parry Jones, M.B., B.S., M.R.C.O.G. Pp. $x+212$, illustrated. London: Butterworth \& Co., Ltd. 1952. 35s.

The 'pros and cons' of any type of forceps depend on so many factors that it is difficult to assess their real value. Parry Jones has analyzed these different factors, not the least of which is the skill of the operator. $\mathrm{He}$ tends to repeat some points, but perhaps this is for emphasis.

The historical summary at the beginning is stimulating, and Kielland's original paper at the end is interesting and repeats Kielland's advice which has been so often disregarded in the past:

'These forceps and their method of insertion are not to be recommended for those who are either unable or unwilling to take these precautions.'

The book provides a summary of the use and abuse of Kielland's forceps, and is a defence of them.

\section{FUNCTIONAL ENDOCRINOLOGY}

By N. B. Talbot, M.D., E. H. Sobel, M.D., J. W. MCArthur, M.D., and J. D. CrawFord, M.D. Pp. $x x x+638$, illustrated. London: Geoffrey Cumberlege. i 952 . 63s.

Advances in endocrinology in recent years have been extremely rapid and there has been a widely felt need for a reliable and reasonably brief account of these advances. This book, which is published under the auspices of the Commonwealth Fund, fulfils this need remarkably well as far as endocrine disorders affect children and adolescents, and the paediatrician who is looking for a guide in this complex subject will find his needs well satisfied. The delays inevitable in the publication of a book of this size make it notoriously difficult to ensure that, when published, it is still reasonably up to date. In this respect the book is more successful than 